\title{
O discuRso MÉdico-CIENTÍfICO ACERCA dA RELAÇÃo epilepsia e trabalho: Prescrições, limites e POSSIBILIDADES AO SUJEITO TRABALHADOR ${ }^{58}$
}

\author{
Vando GOLFETTO* \\ Jarbas DAMETTO* \\ Cleide Fátima MORETTO ${ }^{* * *}$
}

RESUMO: O ensaio busca problematizar as concepções relativas à epilepsia e, em especial, ao discurso médico-científico sobre as relações existentes entre essa doença e a vida de trabalho. A partir de uma revisão de literatura não exaustiva, são retomados elementos históricos e conceituais, tendo como objetivo identificar como a epilepsia foi concebida no ocidente até ser encampada pelo saber científico e como esse saber discorreu a respeito da capacitação ou da incapacitação do sujeito acometido para o trabalho remunerado. Constata-se que, declinado o discurso pré-moderno, a ciência médica apropria-se da epilepsia, dando a ela o status de doença orgânica. Entretanto, o estigma, antes incitado por interpretações obscuras, não foi extinto, interferindo na relação do sujeito acometido com o outro, sobretudo quando se compreende que trabalhar é uma forma de relação social, em que o corpo e a subjetividade estão envolvidos. Nota-se que argumentos técnicos sustentados na perspectiva do risco e da segurança geram prescrições limitadoras à vida laboral, leitura esta, ponderada em âmbito acadêmico por discursos que visam preservar a autonomia pessoal na epilepsia, havendo a coabitação desses discursos na contemporaneidade. Os pressupostos

\footnotetext{
58 O presente trabalho foi realizado com apoio da Coordenação de Aperfeiçoamento de Pessoal de Nível Superior - Brasil (CAPES) - Código de Financiamento 001.

* UPF - Universidade de Passo Fundo. PPGEH - Programa de Pós-Graduação em Envelhecimento Humano. Passo Fundo - RS - Brasil. 99052-900 - vando.golfetto@hotmail.com. https://orcid.org/00000002-0518-123X.

** UPF - Universidade de Passo Fundo. PPGEH - Programa de Pós-Graduação em Envelhecimento Humano. Passo Fundo - RS - Brasil. 99052-900 - jarbasdametto@gmail.com http://orcid.org/0000-00032053-984X

*** UPF - Universidade de Passo Fundo. PPGEH - Programa de Pós-Graduação em Envelhecimento Humano. Passo Fundo - RS - Brasil. 99052-900 - moretto@upf.br. https://orcid.org/0000-0003-22847555.
} 
foucaultianos relativos a tais discursos, na perspectiva do saber-poder, permitem ampliar a lucidez acerca da efetiva materialidade orgânica desse mal, destacando-a da apreensão discursiva do fenômeno e seus efeitos.

PALAVRAS-CHAVE: Epilepsia. Trabalho. Subjetividade.

\section{Introdução}

Epilepsia é uma condição neurológica constituída por diversas etiologias que englobam múltiplas síndromes e diferentes tipos de crises epilépticas recorrentes devido a atividades anormais do cérebro (TEDRUS et al., 2012; ALMEIDA, 2010). A denominação epilepsia, refere-se a um grupo de doenças que apresentam, como fator comum, a presença de crises epilépticas, que não são, porém, consequência de condição tóxico-metabólica inadequada ou de febre (GOMES, 2009; SCHMIDT; STAVEM, 2009; FERNANDES; DIAS, 2017).

O número de pessoas acometidas de epilepsia chega a, aproximadamente, 60 milhões de pessoas em todo o mundo (OPAS, 2011, FERNANDES; DIAS, 2017, OMS, 2017). De tal forma, ela se configura como um problema de saúde pública que afeta indivíduos de todas as raças e sexos e nas mais diferentes idades. Para além da amplitude de sua incidência, a epilepsia ganha relevância devido ao seu efeito no âmbito psicossocial e econômico, em face à diversidade de limitações no desempenho de atividades ou de restrições atribuídas à doença.

Estimativas do Ministério da Saúde (BRASIL, 2013) informam que, no Brasil, há 157.070 novos casos de epilepsia por ano (incidência de 100/100.000 habitantes), sendo que a sua taxa de prevalência está entre $1 \%$ e $1,5 \%$, o que significa algo entre 1.570 .701 e 2.356 .052 casos. Esses dados demonstram o quanto a doença está presente no cotidiano de diversos indivíduos brasileiros, repercutindo na rotina de suas famílias, pelas dificuldades de inserção em atividades sociais e econômicas (PINTO, 2014; BRAGA; GIANVECCHIO, 2014).

Ao trabalhador com epilepsia são impostas restrições funcionais, sendo considerado um indivíduo de risco para si e para terceiros, como a possibilidade de danos materiais em caso de crise e de acidentes, contribuindo para a existência de restrições em termos da sua empregabilidade. Além da percepção e da atitude dos empregadores no que diz respeito à vinculação ao emprego, ao salário e ao posto de trabalho que o sujeito ocupará, as escalas, as possibilidades ou não de ascensão na empresa e o tempo de permanência no emprego são apresentados como preocupações, 
sobretudo em atividades profissionais com nível de risco ocupacionais mais altos (MIZIARA; MIZIARA; MUÑOZ, 2011; PINTO, 2014; BRAGA; GIANVECCHIO, 2014).

Frente à relevância social do tema e às implicações objetivas na vida dos sujeitos acometidos de epilepsia, este ensaio, de natureza reflexiva e interpretativa e ancorado em uma revisão não exaustiva de literatura, pretende problematizar o discurso médico-científico acerca desse mal, principalmente no que se refere à vida ocupacional desse público. Busca-se com isso, suspender a noção de preconceito que ronda as apreciações do senso comum acerca da relação entre empregabilidade e epilepsia e levantar, no texto científico, os argumentos que instituem esses sujeitos limitados para o trabalho. Para tal, constrói-se uma breve genealogia da epilepsia enquanto experiência social, analisando o discurso científico e seus efeitos políticos, tal como proposto pelo pensamento de Michel Foucault (1984; 2002a; 2002b; 2006; 2008).

\section{Epilepsia: aspectos históricos e conceituais}

A epilepsia não se limita a recortes sociais, étnicos, geográficos, etários ou de gênero, estando presente nos mais diversos períodos históricos. Seu conceito é elaborado e reelaborado com diferentes terminologias e etiologias, dependendo das características epistemológicas de cada época, sendo hodiernamente tomado como um transtorno neurológico crônico grave, presente em todas as sociedades (GOMES, 2006, 2009). Embora sua onipresença remeta a uma etiologia orgânica, sua interpretação sempre sofreu importantes vieses culturais.

A doença é descrita ao longo dos séculos, supondo-se que os primeiros casos remetam ao período Neolítico (aproximadamente 10.000 a 4.000 a.C.), do qual restaram ossadas com sinais de trepanação craniana, atos supostamente realizados em episódios de situações convulsivas e outras desordens neurológicas (COSTA, 2014; PASSOS, 2017). Os primeiros registros escritos sobre a epilepsia têm origem em torno de 2.000 a.C. na Antiga Mesopotâmia, redigidos na língua Acadiana em um documento que descreve um episódio convulsivo e atribui ao fenômeno um caráter mágico e sagrado relacionado à manifestação de espíritos do mal ou à uma expressão de descontentamento divino (BRUNO NETO, 2014; PASSOS, 2017).

Bruno Neto (2014) indica que relatos sobre a epilepsia podem ser encontrados em textos médicos do Antigo Egito, como o papiro cirúrgico de Edwin Smith, datado do ano de 1700 a.C., ou o Sakikku, um conjunto de várias tábuas, que 
constitui um dos mais antigos textos médicos babilónicos de 1067 a 1046 a.C., no qual duas delas referem-se a quadros equiparáveis à epilepsia e descrevem, principalmente, as suas características clínicas.

A interpretação da Grécia antiga, como descrevem Almeida (2010) e Costa (2014), remonta a um período no qual todas as doenças eram tidas como consequência de ataques ou possessões por parte dos deuses e demônios. Essa cultura concebia um mundo assombrado por espíritos maléficos e acreditava que as doenças eram sinais de desagrado divino ou de intrusão de demônios. O tratamento implicava em acalmar o deus ou exorcizar o demônio que havia possuído o corpo do paciente, por meio da realização de rituais que eram baseados em encantamentos e sacrifícios e que podem ser identificados em documentos antigos da história da Medicina Grega e nas obras épicas de Homero (séc. VIII a.C.) e Hesíodo (séc. VIII/VII a.C.). Conforme Magiorkinis, Sidiropoulou e Diamantis (2011), nesse período a epilepsia foi considerada um castigo divino para os pecadores e era, muitas vezes, associada à deusa da lua; dependendo dos sintomas, poderia ser também atribuída a outros deuses. Por tais motivos, a epilepsia era denominada doença sagrada.

Brodie, Schachter e Kwan (2012) citam diversos médicos na Antiguidade que realizaram uma descrição formal da doença, dentre eles Alcmeon de Crotona (séc. VI a.C.), que situou o cérebro como o órgão da cognição, fonte da memória e dos pensamentos e, provavelmente, a fonte do fenômeno epilético. Na sequência, apresentam Demócrito de Abdera (séc. V a.C.) que dedicou um livro à epilepsia, indicando que o cérebro abrigava a aparição, a cognição e os sentidos. Os autores ressaltam que, no entanto, a primeira descrição formal da epilepsia enquanto doença, está incluída no Corpus Hipocraticum, de autor desconhecido. Comentam que essa descrição é atribuída, por muitos autores, a Hipócrates, considerado o pai da Medicina, que viveu em 400 a.C. No Corpus Hipocraticum há críticas ao caráter de doença sagrada e contagiosa atribuído à epilepsia, considerando-a como qualquer outra doença de causa orgânica. Observam que, mesmo existindo definições orgânicas para a doença desde a antiguidade, na maior parte das culturas, ela seguiu sendo interpretada como algo demoníaco e sobrenatural, devido à forma de manifestação de seus sinais e sintomas.

$\mathrm{Na}$ Roma antiga, as pessoas com epilepsia eram impedidas de participar de atividades comunitárias em razão do medo de contágio, pois quem estava acometido da doença era considerado impuro. Há relatos de que sempre que algum cidadão sofria um ataque epilético em espaços públicos, suspendiam-se os comícios, razão pela qual denominavam essas crises de mal comicial (COSTA, 2014, BRUNO NETO, 2014, PASSOS, 2017). 
Na Idade Média, a epilepsia também foi tomada como uma afecção da alma e um mal passível de contágio. Sua classificação era caracterizada pelo misticismo e pelo dogmatismo religioso reinante em todos os campos das ciências, incluindo a medicina (COSTA, 2014). Durante o período da Santa Inquisição, os acometidos pelo sofrimento mental e pela epilepsia, também foram perseguidos, pois toda doença de etiologia desconhecida poderia ser considerada como feitiçaria, em um período no qual Deus era considerado árbitro da vida, das doenças e da morte (ALMEIDA 2010; MAGIORKINIS; SIDIROPOULOU; DIAMANTIS, 2011).

No Renascimento europeu observa-se a tentativa de se ver a epilepsia como uma manifestação de doença física em lugar de uma causalidade mística, mas é no período do Iluminismo que a epilepsia começa a ser considerada em sua forma moderna. Os médicos da época focalizaram os estudos sobre a doença, desenvolvendo teorias em relação ao mecanismo das crises, apoiados nos avanços da anatomia (GOMES, 2006; BRUNO NETO, 2014). De acordo com esses autores, no século XIX, sob forte influência do positivismo, diversos estudos nas áreas da neurofisiologia são firmados, dando subsídios aos estudos das doenças cerebrais, dentre as quais a epilepsia. Nesse período, como argumenta Canguilhem (2009), a identidade real dos fenômenos definidos como vitais normais e patológicos passou a ser vista como uma espécie de dogma garantido cientificamente, determinado pela autoridade atribuída a biólogos e médicos.

Esse recorte histórico pode ser concebido como a ascensão do paradigma biomédico em relação a esse objeto, o que implica em uma delimitação epistemológica de inspiração newtoniana e cartesiana que situa no corpo, em uma concepção físicomecanicista, a experiência de adoecimento (NASCIMENTO et al., 2013). Nesse contexto, a epilepsia passa a ser objeto da especialidade médica, sujeita às prescrições curativas e normativas de campos cada vez mais específicos e, frequentemente, fragmentados, de práticas e saberes médicos.

No período subsequente, observou-se a introdução das especialidades médicas nos diferentes domínios da Anatomia, Fisiologia, Patologia, Terapêutica e da Cirurgia (ALMEIDA, 2010). Entre as principais demandas a esses saberes específicos estava a necessidade de solucionar os problemas de saúde de um público mais exigente. A Neurologia é elevada ao status de uma nova ciência, afastada da Psiquiatria, e, a partir disso, os acometidos de epilepsia são encaminhados e tratados em locais especializados.

A partir dessa nova perspectiva, como apontam Brodie, Schachter e Kwan (2012) e Costa (2014), diferentes terapias para a doença foram sugeridas por vários pesquisadores, porém, um em especial é considerado o pai da epilepsia: o 
neurologista inglês John Hughlings (1835-1911). Foi ele quem elaborou o conceito de crise epiléptica como uma atividade cerebral desordenada originada de áreas do córtex cerebral que desempenha papel central em funções mais complexas da mente, como atenção, consciência, linguagem, percepção e pensamento. Suas pesquisas e achados clínicos, mais tarde, são comprovados por seus adeptos por meio de experimentos anatômicos, marcando um período da origem da compreensão contemporânea da natureza da epilepsia e início da terapêutica médica, razoavelmente eficaz (BRUNO NETO, 2014; PASSOS, 2017). Cervelini et al. (2008) explicam que nos séculos XIX e XX, autores como Gowers, Wilson, Merritt, Jasper situaram a epilepsia como uma doença orgânico-cerebral, porém, apenas na década de 1980 foi introduzido o termo, síndrome epiléptica.

Com a evolução dos estudos da epilepsia, ocorrem inúmeros avanços na área da neurologia, solidificados por progressos no domínio da neurofisiologia, no âmbito do sistema nervoso e por novos meios de diagnóstico. Esses progressos contribuíram para uma melhor compreensão das patologias subjacentes ao sistema nervoso e abriram caminho para apropriação da epilepsia pela Neurologia e para a construção de um saber ainda mais delimitado: a Epileptologia (COSTA, 2014).

Experimentos mais detalhados ao tratamento das pessoas com epilepsia aconteceram ao mesmo tempo em que colônias para emprego e cuidado das pessoas com epilepsia eram implantadas em diversos países da Europa (ALMEIDA, 2010; PASSOS, 2017). Dessa forma, o mito da doença como uma maldição estaria aparentemente vencido nas culturas modernas, porém, a doença ainda permanece como uma marca social para muitas pessoas acometidas e, por conseguinte, são necessárias medidas de cautela com as suas necessidades psicológicas e sociais frente aos avanços da tecnologia e às novas definições conceituais. Nota-se que os avanços teóricos e técnicos não foram suficientes para a mudança efetiva na compreensão geral sobre a doença, seja pelas marcas culturais que a epilepsia ainda carrega, seja pelas prescrições limitadoras decorrentes do saber médico-científico.

A breve retomada histórica supra desenvolvida demonstra continuidades e rupturas na interpretação da epilepsia, bem como a coabitação de perspectivas discrepantes em determinadas épocas. Há alguns séculos, a racionalidade místicoreligiosa perdeu espaço no discurso sobre essa síndrome, entretanto, a apropriação médico-científica da epilepsia não significou o término das restrições à vida plena desses sujeitos. Em meio a tal racionalidade, fragmentária em sua concepção original, a integralidade do cuidado de pessoas acometidas de doenças crônicas e complexas, que refletem perniciosamente não apenas nos órgãos acometidos, mas em toda a 
existência do sujeito, tornou-se um desafio prático e epistemológico difícil de transpor (TESSER; LUZ, 2008).

A redenção pela técnica, promessa da Modernidade, mostrou-se falaciosa, cabendo uma crítica ao discurso contemporâneo derivado dessa racionalidade. Sobre esse aspecto, é oportuna a visão de Canguilhem (2009) de que o homem, ainda que apreendido pelo aspecto físico, não está limitado ao seu organismo. Nas suas palavras, "o homem, tendo prolongado seus órgãos por meio de instrumentos, considera seu corpo apenas como um meio de todos os meios de ação possíveis. É, portanto, para além do corpo que é preciso olhar, para julgar o que é normal ou patológico para esse mesmo corpo" (CANGUILHEM, 2009, p.79). A grande contribuição desse autor foi a inclusão do conceito de normatividade, a partir de noções de saúde e de doença. Para ele, a saúde é uma norma de vida superior que está associada à capacidade de os sujeitos superarem a doença e as modificações do meio, com a criação de suas próprias normas (BRITO, 2017). Nota-se aí, a necessidade de problematizar a normatividade derivada da concepção de saúde como ausência de patologia, principalmente diante da incurabilidade e da cronicidade, tal qual experimentado na epilepsia. Diante de tal propósito, é sobre o discurso acadêmico-científico como fonte de limitação, ou também como resistência à limitação, que se dedicam as próximas linhas.

\section{Epilepsia: restrições e possibilidades frente ao mercado de trabalho}

Tedrus et al. (2012) e Braga e Gianvecchio (2014) definem epilepsia como uma condição neurológica constituída por diversas etiologias que englobam múltiplas síndromes e diferentes tipos de crises epilépticas recorrentes, devido a uma atividade neuronal exacerbada no cérebro. Concluem que a epilepsia não é uma doença ou síndrome específica, mas sim, uma categoria de sintomas complexos resultantes de alterações da função cerebral.

O diagnóstico da epilepsia é feito tendo por base a existência de crises epilépticas (PINTO, 2014, HOPKER et al., 2016, HOELLER et al., 2016). Trata-se de uma doença afeta indivíduos de todas as raças, de ambos os sexos e nas mais diferentes idades; é considerada um problema de saúde pública devido ao seu efeito no âmbito psicossocial e econômico (PASSOS, 2017). Além do sofrimento psíquico e da falta de cuidados adequados, as pessoas acometidas pela epilepsia vivenciam o estigma, a vergonha, a exclusão social e, com alguma frequência, a morte (HOPKER et al., 2016). 
As dificuldades sociais geram consequências graves diretamente sobre a qualidade de vida das pessoas com epilepsia, pois tratar dessas pessoas não significa somente realizar exames, ter cuidados com as medicações, mas observar o seu comportamento envolvendo escola, trabalho e sociedade (FERREIRA et al., 2012). Para Miziara, Miziara e Muñoz (2011) e Hopker et al. (2016), o impacto da epilepsia é determinado por fatores psicológicos e sociais, bem como pela percepção das pessoas com epilepsia e de seus familiares acerca das implicações de tal doença em suas vidas, sobretudo, em decorrência da dificuldade de o trabalhador entender a sua própria condição de saúde. Para esses autores, as pessoas com epilepsia deparam-se com dificuldades: em relação ao trabalho, encontrar ou manter uma atividade laboral; diante das restrições que enfrentam e por serem vítimas de preconceito.

Goffman (2002), ao tratar da relação do eu na vida cotidiana, chama a atenção para a importância das primeiras impressões suscitadas no entorno social. Nessa perspectiva, defende que, no momento em que um sujeito se apresenta diante de outros, possui razões para tentar controlar a impressão com que esses outros perceberão a situação. No âmbito do trabalho, o ajuste do sujeito ao espaço pretendido dependerá da sua capacidade em tomar e conservar a iniciativa em relação ao posto pretendido. Esse indivíduo responderá às projeções iniciais estabelecidas pelos demais, assumindo ser uma pessoa de determinado tipo e se coloca no compromisso "de exercer uma exigência moral sobre os outros, obrigando-os a tratálo e valorizá-lo de acordo com o que as pessoas do seu tipo tem o direito de esperar" (GOFFMAN, 2002, p.21).

Sem mesmo a chance de buscar se ajustar a um posto de trabalho, a pessoa com epilepsia é frequentemente afastada do mercado do trabalho mesmo antes de sua inserção, o que causa apreciações negativas sobre si próprio. As diversas questões associadas aos trabalhadores com epilepsia são frequentemente consideradas em empresas, elencando-se diversos motivos para o empregador preteri-los: o medo que as crises originem acidentes; suposição de que eles possuem menor capacidade de trabalho e, de imediato, baixa produtividade; crença de que esses sujeitos faltam mais ao trabalho em virtude das crises; receio de que ocorram crises epilépticas no local de trabalho e gerem intranquilidade nos demais empregados e que a produtividade diminua; além do estigma que, culturalmente, recai sobre o sujeito mental ou neurologicamente doente (FERREIRA et al. 2012; NICKEL et al., 2011). A pessoa com epilepsia é considerada muito suscetível a acidentes (MIZIARA, MIZIARA, MUÑOZ 2011; BRAGA; GIANVECCHIO, 2014). Afirma-se que seu nível funcional de atuação é adequado, porém as oportunidades são negadas devido ao receio do empregador, e, mesmo nas áreas de adaptação social em que os sujeitos com epilepsia 
poderiam ter participação normal, há restrição por parte da sociedade, ancorada em falsos pressupostos.

Pinto (2014) relata que empregadores, em sua maioria, consideram que a epilepsia compromete o trabalho, sobretudo por dificuldades ligadas à atuação no trabalho remunerado. Destaca que, entretanto, essa posição não é consensual. Há empregadores que ponderam que a epilepsia não intervém no trabalho, o que constatam na atuação satisfatória do trabalho de funcionários acometidos. A esse respeito, Braga e Gianvecchio (2014) exibem uma lista de profissões que deveriam ser evitadas por pessoas com epilepsia, entre as quais estão: policiais, bombeiros, vigias solitários, instrutor de natação e salva-vidas, babás, profissionais de enfermagem, cirurgiões, motoristas profissionais, operadores de máquinas e/ou equipamentos, militares, profissionais que executam trabalhos em altura ou com uso de escadas. Os autores apontam para necessidade de cautela na consideração dessa proposta, indicando sua aplicação absoluta apenas nos casos em que não haja completo controle do quadro. Para os demais, as restrições podem ser relativizadas.

Sarmento e Minayo-Gomez (2000) e Pinto (2014) destacam que, em função das limitações no desempenho do trabalho em decorrência da própria epilepsia e das crises, bem como dos efeitos colaterais da medicação, as pessoas com epilepsia recorrem à economia informal como meio de sustento econômico, aumentando a vulnerabilidade social desses sujeitos. Esse conjunto de situações eleva as taxas de desemprego e estimula o trabalhador a viver na informalidade, no subemprego, na dependência econômica da família. A previdência social dispõe de uma organização de amparo que garante aos seus segurados a reposição da renda quando da perda da aptidão de trabalho, como a aposentadoria por invalidez, auxílio doença, auxílio acidente e reabilitação profissional. Porém, falhas na legislação e em um conjunto de regras nos critérios de avaliação do diagnóstico da epilepsia, juntamente com a baixa confiabilidade das informações fornecidas pelo segurado, além da falta de um marcador para confirmação de epilepsia ativa, dificultam a comprovação da incapacidade laborativa, gerando, frequentemente, o indeferimento de solicitação de benefício, o que causa prejuízos consideráveis dos pontos de vista pessoal e social (FERREIRA et al., 2012).

Para Minayo, Hartz e Buss (2000) e Miziara, Miziara e Muñoz, (2011), outro fato relevante é o alto índice de pessoas com epilepsia aposentadas por invalidez, considerando-se o indivíduo incapaz para o trabalho e insuscetível de reabilitação para o exercício da atividade que lhe garanta subsistência. Os autores sustentam que há diferença entre a pessoa com epilepsia que está profissionalmente ativa e a que está inativa, dado que a invalidez profissional interfere de forma significativamente 
negativa na qualidade de vida desses sujeitos, pois a falta de trabalho ou a impossibilidade de trabalhar tem efeitos negativos no âmbito psicossocial do indivíduo. Portanto, a qualidade de vida, tomada como uma representação social criada a partir de parâmetros subjetivos, como bem-estar, felicidade, amor, prazer, realização pessoal, e também objetivos, cujas referências são a satisfação das necessidades básicas e das necessidades criadas pelo grau de desenvolvimento econômico e social de determinada sociedade, podem sofrer marcante interferência decorrente da epilepsia, e supõe-se, tanto mais quando essa se apresenta como um entrave ao trabalho (OMS, 2017).

O trabalhador com epilepsia, dado o contexto adverso, costuma não revelar a sua condição de saúde ao empregador (FERREIRA et al., 2012), acreditando que ao revelar corre o risco de enfrentar o estigma da doença. A esse respeito Goffman (1988) afirma que a situação especial do sujeito estigmatizado é que a sociedade o enquadra como um membro do grupo mais amplo, portanto, como um ser humano normal, todavia, o informa de que ele é, em certa medida, diferente sendo que não é adequado negar essa diferença. Portanto, para Goffman (1988), a diferença, em si, deriva de uma interpretação sociocultural. Isso porque, em termos gerais, antes de assumir importância, ela necessita ser coletivamente conceitualizada pela sociedade. Nesses termos, um sujeito que, de outro modo, poderia ter sido acolhido facilmente na relação social quotidiana, sinaliza um traço ou atributo que chama a atenção e afasta aqueles que ele encontra, impedindo a possibilidade de que seja dada atenção aos seus outros atributos.

Goffman (1988) destaca que, desde os tempos de Hipócrates, os sujeitos que descobriam possuir a doença enfrentavam um eu fortemente estigmatizado por meio dos mecanismos definicionais da sociedade. De acordo com o autor, esses mecanismos permanecem mesmo nos casos em que o dano físico causado pela doença seja insignificante. Observa que especialistas empregam o termo epilepsia, para se referirem apenas aos casos em que não é possível identificar uma causa médica específica, o que implicaria em estigma menor.

Para Goffman (1988), nesse caso, a ciência médica deveria retratar-se em relação ao fato de que a sociedade pode agir de maneira mais determinativa. De outra parte, o sujeito suscetível a ataques epilépticos está exposto ao caso mais extremo: "quando recobra a consciência, pode descobrir que está deitado na rua, com incontinência, gemendo e sacudindo-se convulsivamente - um descrédito para a sanidade mental que só é atenuado pelo fato de ele não estar consciente durante parte do episódio" (GOFFMAN, 1988, p.74). O autor acrescenta que cada grupo de 
estigmatizados costuma ter um repertório próprio daquilo que ele denomina de relatos de advertência sobre uma exposição embaraçosa.

Essa perspectiva revela conexões ainda mais complexas quando se analisa a relação entre trabalho, corpo e subjetividade. Conforme Dejours (2004), o trabalho é muito mais que uma atividade, pois constitui-se em uma forma de relação social, implicando em um mundo humano que se caracteriza por relações de desigualdade, de poder e de dominação. Para Dejours (2004, p.31), "trabalhar é engajar sua subjetividade num mundo hierarquizado, ordenado e coercitivo, perpassado pela luta para a dominação" e, por esse motivo, explica que o "real do trabalho" não equivale ao que ele denomina "real da tarefa", amplia-se "à experiência da resistência do mundo social; e, mais precisamente, das relações sociais, no que se refere ao desenvolvimento da inteligência e da subjetividade. O real do trabalho, não é somente o real do mundo objetivo; ele é, também, o real do mundo social" (DEJOURS, 2004, p.31). O autor chama a atenção para a importância do encontro entre o corpo e o real do mundo, no modo como ele concretiza a experiência do trabalho a partir do desenvolvimento da subjetividade. $O$ trabalho não se reduz a uma atividade de produção no mundo objetivo, pois ele coloca à prova a subjetividade, podendo ter implicações fortalecedoras ou de fragilização. Na sua concepção, "trabalhar constitui, para a subjetividade, uma provação que a transforma. Trabalhar não é somente produzir; é, também, transformar a si mesmo e, no melhor dos casos, é uma ocasião oferecida à subjetividade para se testar, até mesmo para se realizar" (DEJOURS, 2004, p.30),

A retomada feita demonstra uma dupla perspectiva acadêmica acerca da relação epilepsia-trabalho. Em uma frente, apresentam-se os riscos implicados na atividade laboral quando executada por uma pessoa propensa a crises epiléticas, um discurso que visa resguardar de dano físico o próprio trabalhador e os demais envolvidos na atividade. Concomitante a isso, há um discurso que visa à autonomia do acometido, sustentando a viabilidade de sua existência como trabalhador e os danos agudos derivados de sua exclusão do mundo do trabalho, ponderações que incitam a relativização da perspectiva anterior por meio de um olhar psicossocial. Em síntese, um discurso prescritivo-limitador, ancorado na perspectiva do risco ou da periculosidade, que se justifica pela forma e imprevisibilidade da crise; e outro, que não se institui efetivamente como uma oposição ao primeiro, mas como uma ponderação necessária aos impactos de seus dizeres. 


\section{O discurso e a subjetivação na epilepsia}

O termo subjetivação designa para Foucault, segundo Revel (2005), um processo pelo qual se obtém a composição de um sujeito, constituindo-se a si próprio em relação aos outros no duplo sentido: de estar assujeitado às práticas de poder, bem como, de (auto)construção de sua própria identidade por meio da consciência ou do autoconhecimento. Ressaltando que a noção de subjetividade se faz pertinente na medida em que permite considerar a indissociabilidade entre individual e coletivo, interior e exterior, individual e social, rompendo com dicotomias que ignoram a intrincada relação entre esses termos. "A raiz não somente da palavra, mas, sobretudo, do conceito de 'subjetividade', remete à experiência de sermos sujeitos, no duplo sentido da palavra (aquele que é submetido e aquele que realiza a ação), em cada tempo e em cada contexto" (RAMMINGER; NARDI, 2008, p.340). Nesses termos, o sujeito em Foucault não é uma essência, mas uma forma, uma forma historicamente situada (CASTRO, 2009).

Em uma perspectiva foucaultiana, o sujeito moderno constitui-se em seus enredamentos em práticas e em saberes. O saber das ciências acerca do homem, como os discursos da área da saúde, bem como a série de prescrições e práticas deles derivados ou neles apoiados, em grande medida, forjam a subjetividade daqueles a quem os enunciados são direcionados. O saber médico e científico não possui neutralidade política, ele opera na condução de sujeitos, e na própria constituição desses, a partir de parâmetros de normalidade e anormalidade (FOUCAULT, 1984; 2006). Como vimos nas contribuições de Canguilhem (2009), juntamente com Foucault (1984, 2002a, 2002b, 2006, 2008), as classificações, do modo como estão dispostas nos manuais diagnósticos contemporâneos seguem a lógica da normalização, o que implica na busca de enquadramento dos sujeitos à norma social vigente (CAMPOS, 2014). Entretanto, não é em uma condição de passividade que sujeitos se tornam objeto de saberes e práticas, tais processos instituem-se em meio a polêmicas e resistências.

Esse sujeito histórico é produzido pela sua própria história enquanto indivíduo, mas transpassado pelas verdades de seu tempo. Como argumentam Souza e Taques (2014), para Foucault, o sujeito se constitui pelos jogos de verdade, aos quais se encontra assujeitado, um assujeitamento que o coloca como sujeito narrado, descrito, alocado pelos discursos, mas também como operador e reprodutor desses. Os jogos de verdade referem-se a um conjunto de regras de produção da verdade, sendo que por verdade, pode-se tomar um conjunto de elementos discursivos, instituídos historicamente em batalhas travadas em um palco político e epistêmico específico, 
capaz de gerar repercussões objetivas sobre a vida das pessoas envolvidas, a partir de consensos e resistências a ela. A verdade produz efeitos subjetivantes que acabam por impregnar a mente, as ações e, em última análise, os corpos dos sujeitos, forjando modos de ser (FOUCAULT, 2002a).

O binômio saber-poder, constitutivo dos jogos de verdade e traduzido na forma de discursos e de práticas, atua sobre sujeitos livres que possuem em sua frente um campo de possibilidades: é na cooptação da liberdade que ocorrem os efeitos subjetivantes que aqui se busca analisar. Poder, em sentido foucaultiano, não denota uma ação violenta, brutal e inescapável, antes, é um fenômeno relacional onipresente, que se situa nas interações entre sujeitos, nas relações entre o sujeito e as verdades de seu tempo, e na experiência do sujeito para consigo mesmo (FOUCAULT, 1984; CASTRO, 2009).

Retomar o discurso acerca da epilepsia a partir de pressupostos foucaultianos seria ampliar a lucidez acerca da efetiva materialidade orgânica desse mal, destacando-a da apreensão discursiva do fenômeno e seus efeitos. Para tal, não é razoável crer na busca da melhor verdade sobre a epilepsia, em uma concepção linear de progresso do saber. Antes, percebe-se frente à retomada realizada nas páginas anteriores, que a história da construção discursiva da epilepsia é composta por rupturas e coabitação de concepções, e que, em cada época, tais discursos geraram seus efeitos, em geral restritivos, na experiência de vida dos acometidos.

Não apenas preconceitos limitam experiências de vida, os conceitos também possuem esse potencial, as verdades, derivadas de qualquer base epistemológica, portam em si o potencial de marcar a existência dos sujeitos. Tal qual problematizado por Foucault (2006), o campo dos males mentais e neurológicos - por afetarem a conduta dos indivíduos, foram encampados por discursos científicos fortemente tramados com preceitos morais, com demandas higienistas e com questões jurídicas, formando um caso exemplar de condução de vidas humanas por meio de enunciados da ciência.

Mantendo uma salutar suspeita frente ao saber técnico-científico, que busca o destituir de qualquer neutralidade política, pontua-se que melhores possibilidades de vida não necessariamente derivarão do avanço da ciência ou da técnica, movimento que se faz necessário, mas não suficiente. Paralelamente às prescrições técnicas que se ancoram no risco e na periculosidade do trabalhador acometido pela epilepsia, cabe evidenciar, com nítida postura crítica e politicamente engajada, as potencialidades desses sujeitos e as viabilidades laborais existentes. Isso significaria ir além das preocupações com a experiência psicossocial na epilepsia, demonstrada por estudos aqui abordados, lançando-se na efetiva construção de uma verdade diversa acerca da 
relação epilepsia-trabalho, capaz de dar aval à resistência do sujeito acometido, em seu ímpeto e necessidade de adequada inserção no mundo laboral.

\section{Considerações finais}

É em um cenário inóspito que se encontram os trabalhadores com epilepsia que buscam um espaço no mercado de trabalho, pois esses indivíduos, além de frequentemente possuírem fragilidades na formação educacional, derivadas ou não de sua condição clínica, sofrem uma seleção impetuosa do mundo contemporâneo, na qual a reestruturação do processo produtivo promoveu profundas repercussões sociais e econômicas, tornando o ambiente de trabalho mais complexo e competitivo, o que produz uma significativa variabilidade de incertezas e exigências adicionais à vida laboral.

Nesse contexto, fica claro que vários são os fatores que influenciam a funcionalidade e a (in)capacidade do sujeito com epilepsia no mundo do trabalho, para além da forma de sua doença, indo desde a falta de informação sobre suas causas, sobre as perspectivas de tratamento e procedimentos a serem utilizados durante uma crise, até a ausência de políticas de formação e empregabilidade específicas para essa parcela da população. Ao considerar a epilepsia como uma condição esporádica ou eventual (como é o caso da maioria das doenças, mas não dessa), e ignorando a cronicidade e a imprevisibilidade da crise como a condição de vida de milhões de cidadãos, obstrui-se os caminhos legais, políticos e epistêmicos para a superação das diversas comorbidades de natureza econômica e psicossocial que se somam à vida desses sujeitos. É como uma população com uma demanda específica que cabe concebê-los.

A própria informação cientificamente embasada, o dado técnico, quando não confrontado com uma racionalidade crítica, desdobra-se em estigmatização, a qual acresce restrições que podem levar a um nível intenso de incapacitação e desvantagens sociais, atravessando não somente a atividade laboral na forma do desemprego ou subemprego, mas a vida por completo, gerando dificuldade para fazer amigos e socializar-se, para formar família. A redução de oportunidades educacionais e de habilidades sociais gera isolamento. É no âmbito do discurso que as verdades desse mundo se estabelecem, como defende Foucault, cabendo resguardar o âmbito polêmico da instituição dos objetos do saber para, assim, permitir-se ao confronto de perspectivas dissonantes, a fim de que nenhuma verdade sufoque as possibilidades de vida. 
Por fim, aponta-se a necessidade de preservar a pluralidade de concepções para que o sujeito-cidadão, com suas necessidades e direitos, possa subsistir ao sujeitopaciente e, com isso, o saber técnico possa apenas gerar melhores experiências de vida, e não boicote às efetivas possibilidades laborais dos acometidos de epilepsia.

\section{THE MEDICAL-SCIENTIFIC DISCOURSE ON THE RELATIONSHIP BETWEEN EPILEPSY AND WORK: PRESCRIPTIONS, LIMITS AND POSSIBILITIES FOR THE SUBJECT WORKER}

ABSTRACT: This paper attempts to question the concepts related to epilepsy, and in particular, the medical-scientific discourse on the relationship between the disease and work life. A non-exhaustive literature review was used to examine historical and conceptual elements, aiming to identify how epilepsy was conceived in the West until it was understood through scientific knowledge, and how this knowledge mediated the capacitation or disablement of the subject undertaking paid work. When the premodern discourse declined, medical science appropriated epilepsy by giving it the status of an organic disease. However, the stigma of epilepsy, previously incited by obscure interpretations, has not been extinguished and it continues to interfere with personal relationships, especially when it is understood that work is a form of social relationship, involving the body and subjectivity. It is noteworthy that technical arguments supported by the perspective of risk and safety generate restrictive prescriptions to working life, while the academic sphere ponders the discourses which aim to preserve personal autonomy for sufferers of epilepsy, and basically these discourses can meet in contemporary times. The Foucaultian assumptions related to such discourses, in the knowledge-power perspective, can increase the lucidity around the effective organic materiality of this illness, emphasizing the discursive apprehension of the phenomenon and its effects.

KEYWORDS: Epilepsy. Work. Subjectivity.

\section{EL DISCURSO MÉDICO-CIENTÍFICO ACERCA DE LA RELACIÓN EPILEPSIA-TRABAJO: PRESCRIPCIONES, LÍMITES Y POSIBILIDADES PARA EL SUJETO TRABAJADOR}


RESUMEN: El ensayo busca problematizar las concepciones relativas a la epilepsia, y en especial, al discurso médico-científico sobre las relaciones existentes entre esa enfermedad y la vida de trabajo. A partir de una revisión de literatura no exhaustiva, se toman elementos históricos y conceptuales, con el objetivo de identificar cómo la epilepsia fue concebida en el occidente hasta ser encampada por el saber científico, y como éste discutía acerca de la capacitación o de la incapacitación del sujeto afectado para el trabajo remunerado. Se observa que, declinado el discurso premoderno, la ciencia médica se apropia de la epilepsia dando a ella el status de enfermedad orgánica, sin embargo, el estigma, antes incitado por interpretaciones oscuras, no ha sido extinguido e interfiere en la relación del sujeto acometido con el otro, sobre todo cuando se comprende que trabajar es una forma de relación social, en la que el cuerpo y la subjetividad están involucrados. Cabe señalar que los argumentos técnicos sostenidos desde la perspectiva del riesgo y de la seguridad generan prescripciones limitadoras a la vida laboral, lectura que se reflexiona en el contexto académico mediante discursos destinados a preservar la autonomía personal en la epilepsia, habiendo la cohabitación de esos discursos en la contemporaneidad. Los supuestos foucaultianos relativos a tales discursos, en la perspectiva del saber-poder, permiten ampliar la lucidez acerca de la efectiva materialidad orgánica de este mal, resaltándola de la aprehensión discursiva del fenómeno y sus efectos.

PALABRAS CLAVE: Epilepsia. Trabajo. Subjetividad.

\section{Referências}

ALMEIDA, Ângela. Sintomatologia Depressiva e Qualidade de Vida na Epilepsia. Dissertação (Mestrado) Psicologia. Universidade da Beira Interior, Covilhã, 2010. Disponível em: <http://hdl.handle.net/10400.6/2584>. Acessado em: 10 jan. 2018.

BRAGA, Ludmila Cândida de; GIANVECCHIO, Victor Alexandre Percínio. Condições norteadoras para caracterização de incapacidade laborativa por epilepsia. Saúde, Ética \& Justiça, São Paulo, v. 2, n. 19, p.67-77, 2014.

BRASIL. Ministério da Saúde. Sistema Único de Saúde - SUS. Departamento de Informática do SUS - Datasus. Informações de Saúde (Tabnet). Brasília, 2013. 
Disponível em: http://www2.datasus.gov.br/DATASUS/index.php?area=0201 Acessado em: 30 mar. 2018.

BRITO, Jussara. Saúde: uma relação com o meio e os modos de vida. Laboreal, Porto, v. 13, n. 1, p. 100-103, jul. 2017.

BRODIE, Martin J.; SCHACHTER, Steven C.; KWAN, Patrick Kwok Leung. Fast facts: epilepsy.5. ed. Albuquerque: Health Press Limited, 2012.

BRUNO NETO, Rafael. Epilepsia: histórico, mitos e tabus. Revista Thema, São Paulo, v.11, n.2, p.47-59, 2014.

CAMPOS, Maria Elisa E. F. G. Norma versus Subjetividade: o legado de Canguilhem. Revista aSEPHallus de Orientação Lacaniana, v. 9, n. 18, p.61-71, maio/out. 2014.

CASTRO, Edgardo. Vocabulário de Foucault: um percurso sobre seus temas, conceitos e autores. Belo Horizonte: Autêntica, 2009.

CERVELINI, Renato et al. Avaliação dos hábitos de atividades físicas de adolescentes com epilepsia do município de Toledo-PR. Journal of Epilepsy and Clinical Neurophysiology, Porto Alegre, v. 14, n. 4, p.155-155, 2008.

COSTA, Vítor António Leal Dias da. A Epilepsia: Contextualização Histórica. Dissertação (Mestrado) - Curso de Medicina, Faculdade de Medicina da Universidade do Porto, Porto, 2014.

DEJOURS, Chistophe. Subjetividade, trabalho e ação. Revista Produção, v. 14, n. 3, p.27-34, set.- dez. 2004.

FERREIRA, Lisiane Seguti et al. Epilepsia e Previdência Social: a decisão médicopericial: -Revista Brasileira de Saúde Ocupacional, São Paulo, v. 126, n. 37, p.330$338,2012$.

FERNANDES, Francisco Cortes; DIAS, João Anastácio. Interpretação da diretriz da Associação Nacional de Medicina do Trabalho (ANAMT) "Epilepsia e Trabalho: Rastreamento" utilizando a razão de verossimilhança. Revista Brasileira de Medicina do Trabalho, São Paulo, v. 2, n. 15, p.167-172, 2017.

FOUCAULT, Michel. Vigiar e punir. 3. ed. Petrópolis: Vozes, 1984. 
A verdade e as formas jurídicas. 3. ed. Rio de Janeiro: Nau, 2002a.

A ordem do discurso. 8. ed. São Paulo: Loyola, 2002b.

O poder Psiquiátrico. São Paulo: Martins Fontes, 2006.

A arqueologia do saber. 7. ed. Rio de Janeiro: Forense Universitária,

2008.

CANGUILHEM, Georges. O Normal e o Patológico. 6.ed. rev. Rio de Janeiro: Forense Universitária, 2009.

GOFFMAN, Erving. Estigma: notas sobre a manipulação da identidade deteriorada. 4. ed. Rio de Janeiro: LTC Editora, 1988.

A representação do eu na vida cotidiana. 10. ed. Petrópolis (RJ): Vozes,

2002.

GOMES, Marleide da Mota. História da epilepsia: um ponto de vista epistemológico.

Journal of Epilepsy and Clinical Neurophysiology, Rio de Janeiro, v. 12, n. 3, p.161-167, 2006.

. Epilepsia e Incapacidade Laborativa. Journal of Epilepsy and Clinical

Neurophysiology, Rio de Janeiro, v. 3, n. 15, p.130-134, 2009.

HOELLER, Alexandre Ademar et al. Epilepsia na senescência: panorama de prognósticos mal compreendidos. Vittalle, Florianópolis, v. 1, n. 28, p.65-74, 2016.

HOPKER, Christiane del Claro et al. A pessoa com epilepsia: percepções acerca da doença e implicações na qualidade de vida. Codas, Curitiba, v. 1, n. 29, p.1-8, 2016.

MAGIORKINIS Emmanouil, SIDIROPOULOU Kalliopi, DIAMANTIS Aristidis. Hallmarks in the History of Epilepsy: From Antiquity Till the Twentieth Century. In: FOYACA-SIBAT H. Novel Aspects on Epilepsy. Rijeka: In Tech, 2011. p.131-156.

MINAYO, Maria Cecília de Souza; HARTZ, Zulmira Maria de Araújo; BUSS, Paulo Marchiori. Qualidade de vida e saúde: um debate necessário. Ciência e Saúde Coletiva, Rio de Janeiro, v. 5, n.1, p.7-18, 2000. 
MIZIARA, Carmen Silvia Molleis Galego; MIZIARA, Ivan Dieb; MUÑOZ, Daniel Romero. Epilepsia e trabalho: quando a epilepsia deve ser considerada incapacitante. Saúde, Ética \& Justiça, São Paulo, v. 2, n. 16, p.103-110, 2011.

NASCIMENTO, Marilene Cabral do et al. A categoria racionalidade médica e uma nova epistemologia em saúde. Ciência e Saúde Coletiva, Rio de Janeiro, v. 18, n. 12, p.3595-3604, dez. 2013.

NICKEL, Renato et al. Estudo descritivo sobre o desempenho ocupacional do sujeito com epilepsia: o uso da CIF como ferramenta para classificação da atividade e participação. Acta Fisiátrica, Curitiba, v. 2, n. 18, p.55-59, 2011.

ORGANIZAÇÃO MUNDIAL DA SAÚDE - OMS. Epilepsia, São Paulo, 2017. Disponível em: <http://saude.ig.com.br/oms-epilep sia.html>. Acessado em: 13 fev. 2017.

ORGANIZAÇÃO PAN-AMERICANA DA SAÚDE - OPAS. A atenção à saúde coordenada pela APS: construindo as redes de atenção no SUS, contribuições para o debate. Brasília, OPAS/OMS, 2011.

PASSOS, Gustavo. História e evolução da cirurgia para epilepsia. Arquivos Brasileiros de Neurocirurgia, Rio de Janeiro, p.1-6, 31 maio 2017.

PINTO, Lauren Machado. A visão do paciente, do familiar e do empregador sobre o trabalho da pessoa com epilepsia de difícil controle. Dissertação. Programa de PósGraduação em Medicina Interna, Área de Concentração em Neurologia, Setor de Ciências da Saúde, Universidade Federal do Paraná, 2014.

RAMMINGER, Tatiana; NARDI, Henrique Caetano. Subjetividade e trabalho: algumas contribuições conceituais de Michel Foucault. Interface (Botucatu), Botucatu, v. 12, n. 25, p.39-346, jun. 2008.

REVEL, Judith. Michel Foucault: conceitos essenciais. São Carlos: Claraluz, 2005.

SARMENTO, Maria Rosa Silva; MINAYO-GOMEZ, Carlos. A epilepsia, o epiléptico e o trabalho: relações conflitantes. Cadernos de Saúde Pública, Rio de Janeiro, v. 16, n. 1, p.183-193, 2000. 
SCHMIDT, Dieter; STAVEM, Knut. Long-term seizure outcome of surgery versus no surgery for drug-resistant partial epilepsy: A review of controlled studies.

International League Against Epilepsy, v. 6, n. 50, p.1301-1309, 2009.

SOUZA, Henrique Pavan Beiro de; TAQUES, Fernando Henrique. Subjetividade e relações de poder no processo de trabalho. Agenda Social Eletronic Journal, São Paulo, v. 8, n. 1, p.1-14, 2014.

TEDRUS, Gloria Maria de Almeida Souza et al. Epilepsia e depressão: aspectos sociodemográficos e clínicos associados. Revista de Ciências Médicas, v. 18, n. 5/6, p.243-250, 2012.

TESSER, Charles Dalcanale; LUZ, Madel Therezinha. Racionalidades médicas e integralidade. Ciência e Saúde Coletiva, Rio de Janeiro, v. 13, n. 1, p.195-206, fev. 2008 .

Recebido em 18/10/2018.

Aprovado em 13/05/2019. 